\title{
Chemical properties of size-selected Au clusters treated under ambient conditions
}

\author{
Dong Chan Lim ${ }^{a}$, Rainer Dietsche ${ }^{b}$, Gerd Ganteför ${ }^{b}$, Young Dok Kim ${ }^{c, *}$ \\ a Department of Surface Technology, Korea Institute of Materials Science. Changwon 641-010, Republic of Korea \\ ${ }^{b}$ Department of Physics, University of Konstanz, D-78457 Konstanz, Germany \\ 'Department of Chemistry, Sungkyunkwan University, 440-746 Cheoncheon-dong, Jangan-gu, Suwon, Gyeonggi-do, Republic of Korea
}

\begin{abstract}
A B S T R A C T
Mass-selected Au clusters consisting of 5-8 atoms deposited on silica were treated with water and aqueous $\mathrm{NaOH}$ solution, and the change of their chemical properties upon these treatments was studied. With water, no change was observed, indicating that the clusters survive as individual entities under such realistic conditions. After immersing the samples into the $\mathrm{NaOH}$ solution, a change of the oxidation behaviors of the Au clusters was found to occur; the originally oxidation resistant $\mathrm{Au}_{5}$ and $\mathrm{Au}_{7}$ become more reactive than the other clusters towards oxidation. Non-scalable chemical behaviors can be obtained from the small clusters even under realistic conditions.
\end{abstract}

\section{Introduction}

When the size of a material is reduced to the nanometer $(\mathrm{nm})$ scale, novel properties such as enhanced catalytic activity appear and, thus, extensive studies have been devoted to the chemical and physical properties of nano-materials [1-3]. Properties of clusters consisting of less than $\sim 100$ atoms depend strongly on each additional atom, and the size dependent change of the physical and chemical properties is abrupt rather than gradual [4-7]. An example of this non-scalable behavior can be found in studies of the oxygen chemisorption rates of free anionic coinage metal ( $\mathrm{Au}, \mathrm{Ag}$ and $\mathrm{Cu}$ ) clusters in the gas phase: even-numbered clusters react more strongly with $\mathrm{O}_{2}$ than their odd-numbered neighbors. which can be explained by an even-odd alteration of the electron affinities of these clusters [7-11].

Using deposited, mass-selected clusters, better insight into the size-selectivity of the chemical and physical properties of clusters, as well as metal-support interactions, can be gained. Previously, the strongly size-dependent variation of the electronic and chemical properties of deposited metal clusters was explored [4-6,1215]. Au clusters were found to show superior catalytic activities to those of the Au bulk crystals. Recently, it was found that the oxidation behavior of Au clusters deposited on silica exhibits an even/ odd alternation analogous to the gas phase data: for clusters consisting of less than 11 atoms, the odd-numbered clusters can readily form Au-oxide upon atomic oxygen deposition, whereas their even-numbered neighbors are more inert [15]. In particular, the pronounced resistance of $\mathrm{Au}_{5}$ and $\mathrm{Au}_{7}$ clusters to oxidation was observed [15].

\footnotetext{
* Corresponding author. Fax: +82312907075

E-mail address: ydkim91@skku.edu (Y.D. Kim).
}

Most of the previous studies using mass-selected clusters in the size regime of non-scalable behaviors were performed under ultrahigh vacuum (UHV) conditions. Therefore, it is not clear whether the information obtained on small clusters under such ideal experimental conditions are valid in real catalysis. In the present study, we attempt to extend the results previously obtained for these clusters to more realistic experimental conditions. Samples containing mass-selected deposited Au clusters were immersed into distilled water and aqueous $\mathrm{NaOH}$ solution. The change of the chemical properties of the clusters after these treatments was investigated by examining their oxidation/reduction behaviors under UHV conditions. We show that the unique and non-scalable behaviors of deposited mass-selected clusters are still preserved after treating the samples under experimental conditions closer to those of real catalysis rather than UHV conditions. Hence, it is likely that the properties of these mass-selected clusters can be exploited in real catalysis. We also show that the chemical properties of the deposited clusters can be easily influenced by additional chemical treatment.

\section{Experimental details}

All the measurements were performed under UHV conditions. For X-ray photoelectron spectroscopy (XPS), a cylindrical hemispherical analyzer (CHA) and an X-ray source with an Al target $\left(K_{\alpha}\right.$, photon energy $=1486.6 \mathrm{eV}$ ) were used. The upper limit of the instrumental resolution of XPS is estimated to be about $1 \mathrm{eV}$. For acquisition of each $\mathrm{Au} 4 \mathrm{f}$ spectrum, $1 \mathrm{~h}$ was required. Si wafers were chemically etched using a mixture of three different acids and water $\left(\mathrm{H}_{3} \mathrm{PO}_{4}, \mathrm{HNO}_{3}, \mathrm{CH}_{3} \mathrm{COOH}\right.$ and $\mathrm{H}_{2} \mathrm{O}$ with a volume ratio of $3: 3: 23: 1$ ). The chemical etching was done in order to increase the defect density of the silica surface, thereby reducing the diffusion of the clusters on the surface, which can cause their agglom- 
eration. For the oxidation experiments, the backsides of the samples were exposed to a hot Pt-filament and, at the same time, the chamber was filled with molecular oxygen $\left(8 \times 10^{-5} \mathrm{mbar}\right)$. This method is known to create atomic oxygen environments, even though the existence of excited molecular oxygen species cannot be completely excluded [16]. After these atomic oxygen treatments, no Pt could be detected using XPS. The exposure time of each sample to atomic oxygen was $30 \mathrm{~min}$.

For the creation of Au cluster anions, a magnetron-sputtersource, originally designed by Prof. Haberland's group in the University of Freiburg, Germany, was used [17]. After extracting the ion beam into a vacuum, the cluster anions were accelerated to $1.5 \mathrm{kV}$. Mass separation was done by means of a $30^{\circ}$ sector magnet with a resolution of about $m / \Delta m=20$. In front of the sample, the clusters were decelerated to the desired deposition energy by applying the corresponding voltage to the sample. The number of clusters deposited on the surface can be counted by measuring the sample current during deposition. Almost identical Au coverages to those of previous studies were used [15]. All the clusters were soft-landed on the surface, i.e., a kinetic energy of less than $0.6 \mathrm{eV}$ per atom was used (most of the clusters had a kinetic energy less than $0.2 \mathrm{eV}$ per atom during deposition). For the deposition of the $\mathrm{Au}$ cluster anions on the substrate, about $\sim 30$ min were required. The measured sample current was about $0.4 \mathrm{nA}$ during deposition. $2 \times 10^{12}$ clusters were deposited on each sample. Considering that the diameter of the area of the cluster deposition is estimated to be $3 \mathrm{~mm}$, the cluster density is suggested to be about $3 \times 10^{13}$ cluster per $\mathrm{cm}^{2}$.

After the clusters had been deposited on the surface, the samples were immersed into the distilled water or $0.1 \mathrm{M} \mathrm{NaOH}$ (purity: 99\%) aqueous solution for $10 \mathrm{~min}$. After these treatments, the samples were immediately inserted into the vacuum system, and oxidation/reduction experiments and XPS-analyses were performed.

\section{Results and discussion}

As has been previously reported, $\mathrm{Au}_{5}$ and $\mathrm{Au}_{7}$ clusters on silica show high inertness towards oxidation upon exposure to atomic oxygen, whereas other clusters smaller than $\mathrm{Au}_{11}$ partially form Au-oxide under the same conditions [15]. The formation of the Au-oxide is evidenced by the appearance of additional peaks at higher binding energies than those of $A u(O)$ in the $A u 4 f$ level spectra (Fig. 1, data taken from Ref. [15]) [18].

In Fig. 2, the Au 4 f level spectra of the NaOH-treated Au cluster samples are displayed, which were obtained after exposure to atomic oxygen. In contrast to Fig. 1., in Fig. 2, the $\mathrm{Au}_{5}$ and $\mathrm{Au}_{7}$ clusters form large amounts of Au-oxide after their exposure to atomic oxygen, whereas the $\mathrm{Au}_{6}$ an $\mathrm{Au}_{8}$ clusters are more inert. There are two conclusions to be drawn from these results:

(i) The oxidation rates still vary dramatically with each additional atom, meaning that the mono-dispersed clusters survived the treatment.

(ii) For the cluster sizes studied herein, the even/odd pattern seems to be inverted. For the gas phase clusters, such behavior occurs if the charge state is altered (see below).

Obviously, the properties of the mass-selected Au clusters deposited on silica are considerably altered by the $\mathrm{NaOH}$-treatment. The oxidized Au clusters can be partially reduced by $10000 \mathrm{~L}$ (Langmuir $=$ mbar $\times \mathrm{s}$ ) of $\mathrm{CO}$ at room temperature (Fig. 3 ), as is evident by comparing the relative amounts of Au-oxide in Figs. 2 and 3.

It is important to mention that when the samples containing $\mathrm{Au}_{7}$ and $\mathrm{Au}_{8}$ clusters are immersed into the distilled water for 5 min each, the unique chemical properties of these clusters are preserved: $\mathrm{Au}_{7}$ is still resistant towards the formation of Au-oxide,

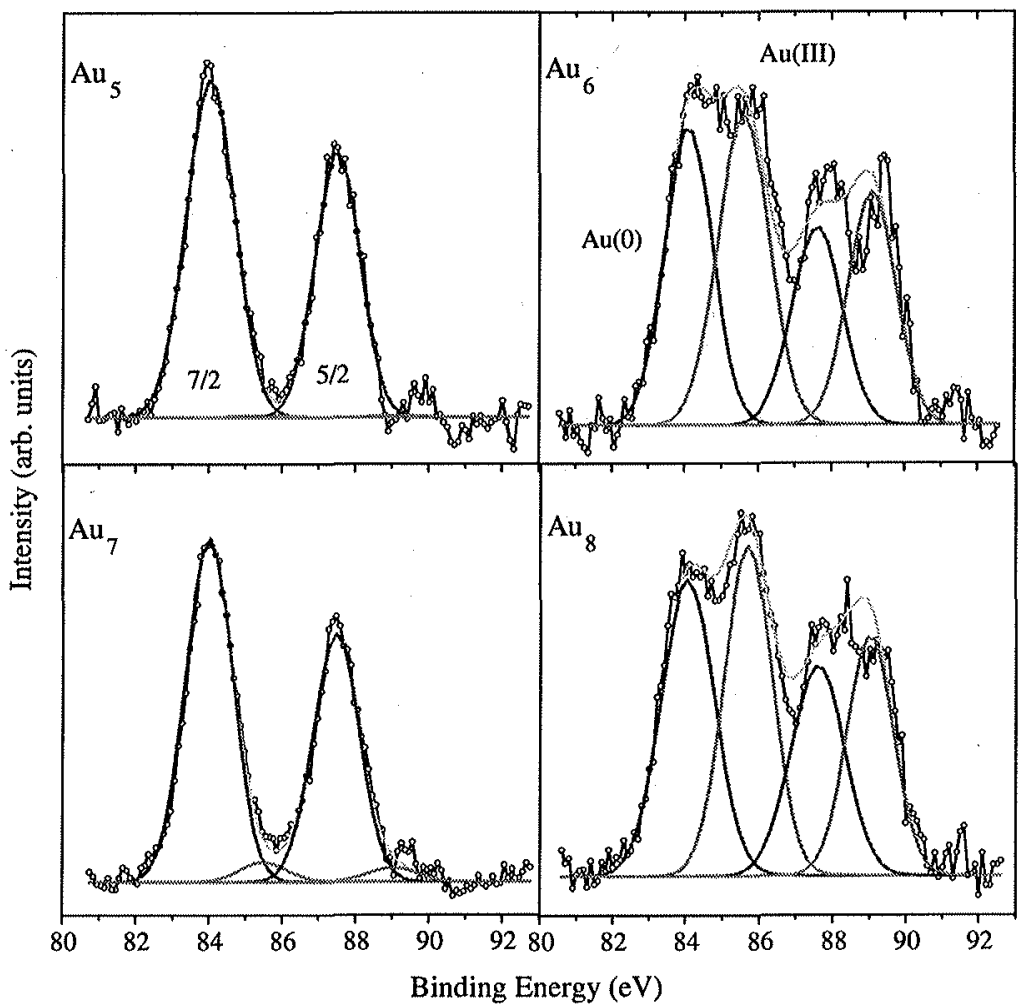

Fig. 1. $\mathrm{Au}_{5}-\mathrm{Au}_{8}$ clusters were deposited on Si wafers covered by native oxide layers under ultrahigh vacuum conditions, and subsequently exposed to atomic oxygen enviromments. After these treatments, Au 4 f level spectrum of each sample was collected. The Au coverage for each sample is estimated to be less than $10 \%$. The even/odd pattern is rather obvious here. 


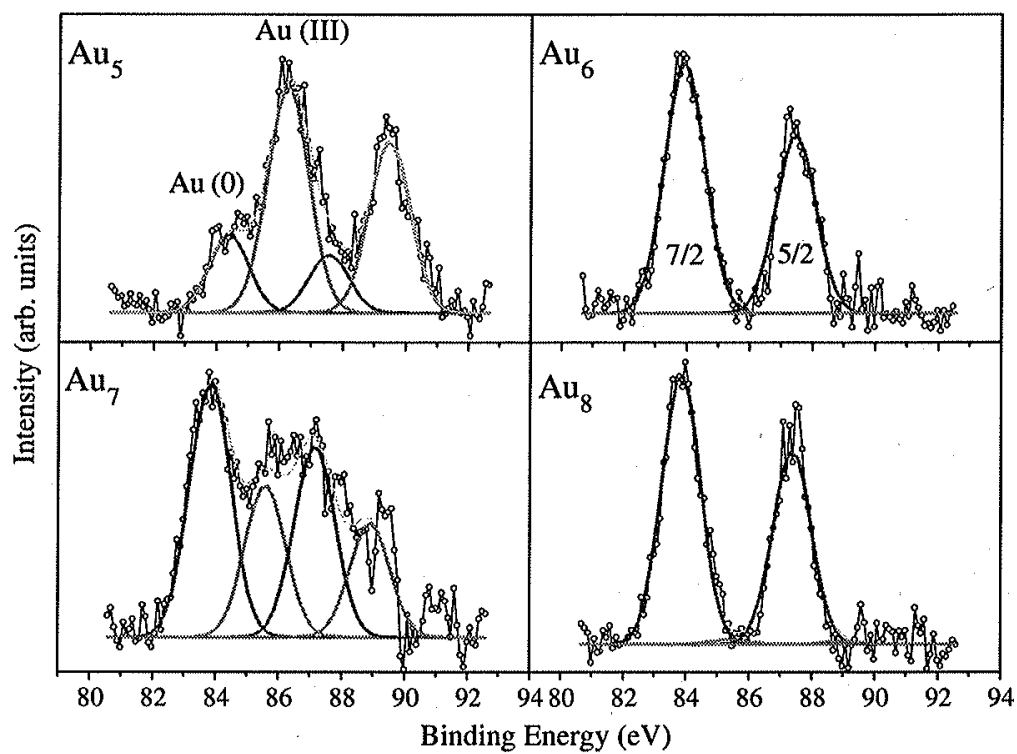

Fig. 2. The Au $4 \mathrm{f}$ level spectra were collected after the samples containing mass-selected and deposited Au clusters had been immersed to the $0.1 \mathrm{M}$ NaOH solution and subsequently exposed to atomic oxygen under high-vacuum conditions. The even/odd pattern is inverted compared to that in Fig. 1.
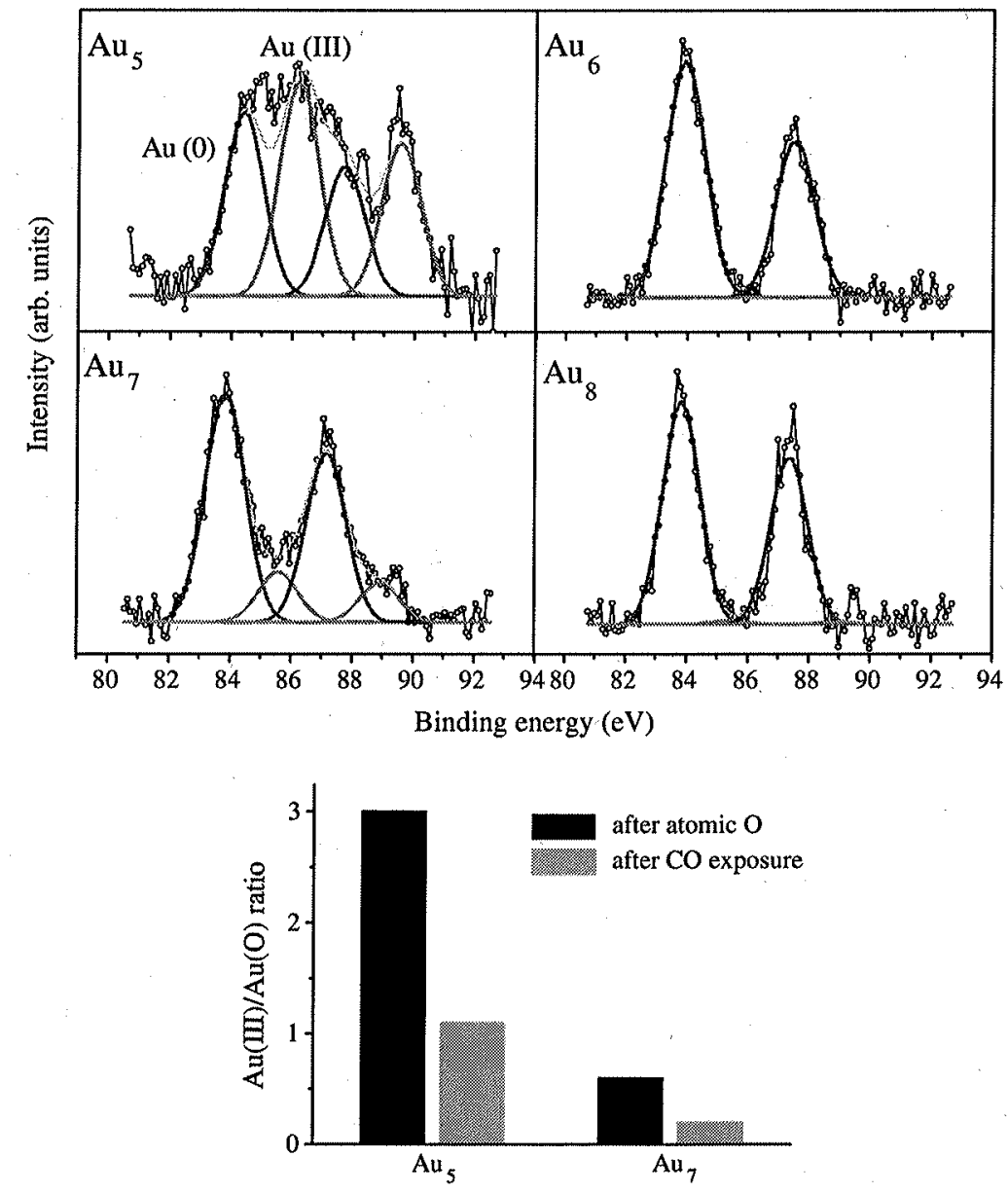

Fig. 3. The Au $4 \mathrm{f}$ level spectra were collected after the samples in Fig. 2 had been exposed to $3000 \mathrm{~L}$ of $\mathrm{CO}$. In the bottom figure, the ratios of $\mathrm{Au}(\mathrm{III})$ to $\mathrm{Au}(\mathrm{O})$ of $\mathrm{Au} \mathrm{H}_{5}$ and $\mathrm{Au}$ before and after $\mathrm{CO}$ exposures are summarized. Exposure to CO results in partial reduction. 
(a) pristine Au nanoparticles larger than $2 \mathrm{~nm}$

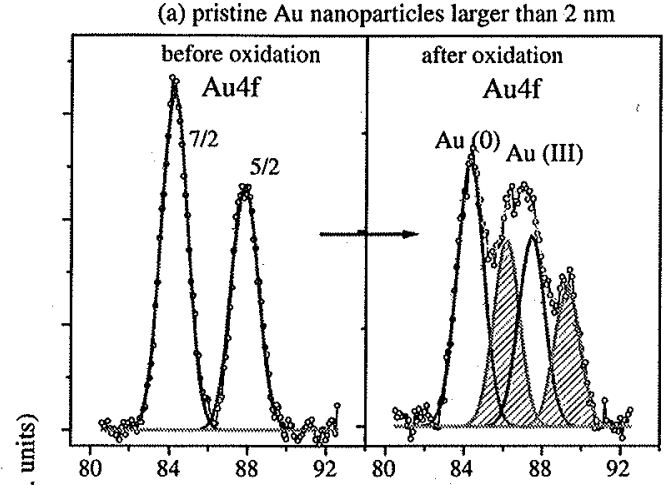

题

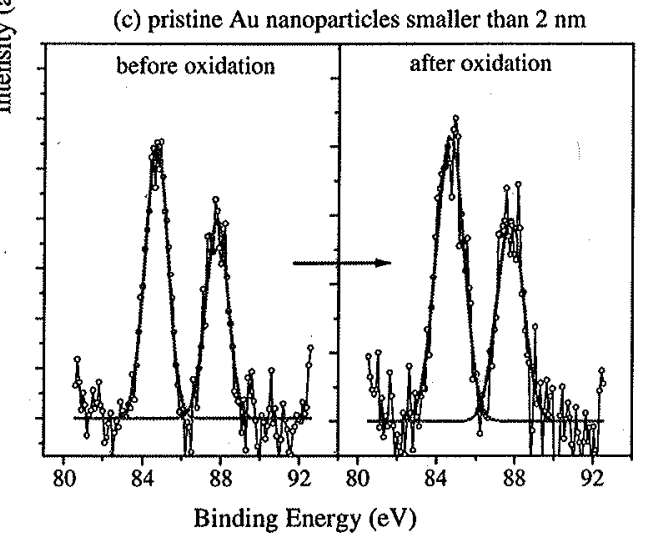

(b) NaOH-treated Au nanoparticles larger than $2 \mathrm{~nm}$

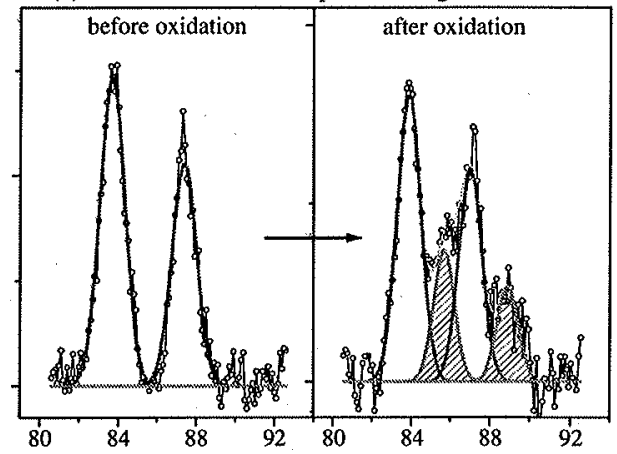

(d) $\mathrm{NaOH}$-treated Au nanoparticles smaller than $2 \mathrm{~nm}$

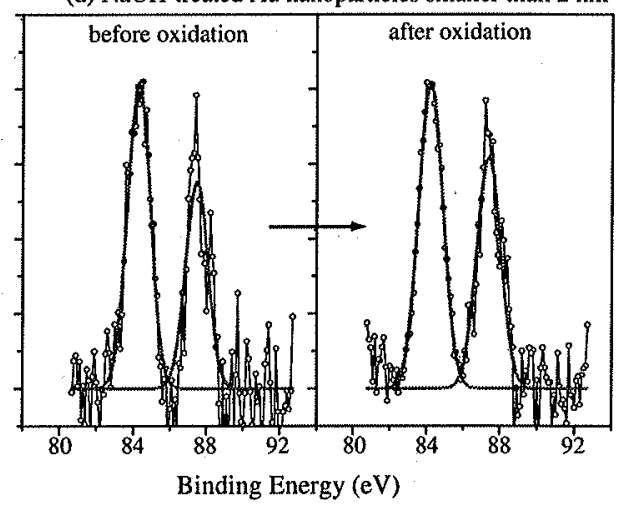

Fig. 4. Top: The Au $4 \mathrm{f}$ level spectra of pristine Au particles larger than $2 \mathrm{~nm}$ in width before and after atomic oxygen exposure. The same sample was immersed into the NaOH solution and then the Au $4 \mathrm{f}$ level spectra were taken before and after the atomic oxygen exposure. Bottom: The Au $4 \mathrm{f}$ level spectra of pristine Au particles smaller than $2 \mathrm{~nm}$ in width before and after atomic oxygen exposure. The same sample was immersed into the $\mathrm{NaOH}$ solution and then the Au $4 \mathrm{f}$ level spectra were taken before and after the atomic oxygen exposure.

whereas $\mathrm{Au}_{8}$ readily forms Au-oxide by reacting with atomic oxygen even after the water-treatment. Air exposures without water treatment showed the same results as those of the water treatments. This result shows that the chemical properties of Au are modified by the solutes of the solution, rather than by water. According to recent theoretical studies, water does only weakly adsorb on Au nanoparticles without dissociation [19].

For comparison, $\mathrm{Au}$ islands grown by evaporating $\mathrm{Au}$ atoms on the same substrate were exposed to atomic oxygen, and subsequently, the Au $4 \mathrm{f}$ level spectra were collected (Fig. 4). We have previously shown that Au islands larger than $\sim 2 \mathrm{~nm}$ in lateral size can be readily oxidized by exposure to atomic oxygen, whereas smaller ones are more inert towards oxidation (Fig. 4) [20]. After immersing the samples containing larger and smaller $\mathrm{Au}$ islands into the aqueous $\mathrm{NaOH}$-solution, the larger islands were still able to be oxidized by atomic oxygen, whereas the smaller islands remained inert, i.e., after the $\mathrm{NaOH}$-treatment, no significant change of the chemical properties of the Au islands was detected. Our result show that the chemical properties of the mass-selected $\mathrm{Au}$ clusters smaller than nine atoms deposited on silica surfaces are unique and much different from those of the larger particles. Moreover, we also show that the chemical properties of clusters smaller than 9 atoms can be modified more easily by additional treatment than those of larger particles.

The origin of the modification of the oxidation behaviors of Au clusters by $\mathrm{NaOH}$ is not well understood yet. The reason for the $\mathrm{Au}_{5}$ and $\mathrm{Au}_{7}$ clusters being more inert towards oxidation before the $\mathrm{NaOH}$-treatment is still questionable as well. In the gas phase studies, a similar inversion of the even-odd pattern in the chemical behavior caused by the attachment of a single $\mathrm{OH}$ group to an $\mathrm{Au}$ cluster was found [21]. This phenomenon was attributed to a single electron transfer from an $\mathrm{Au}$ cluster to an $\mathrm{OH}$ group. One can imagine that the attachment of a single $\mathrm{OH}$ or $\mathrm{Na}$ to an Au cluster on silica can result in an opposite even-odd pattern in the oxidation behavior; however, it is not likely that our samples experienced a one-electron change of the valence electronic structure by simply immersing them into $\mathrm{NaOH}$ solution. It is possible that silica, $\mathrm{NaOH}$ (possibly contaminated by $\mathrm{Na}_{2} \mathrm{CO}_{3}$ ) and $\mathrm{Au}$ form a mixed complex. It can also be postulated that the deposition of $\mathrm{Na},-\mathrm{OH}$ groups, $\mathrm{NaOH}$ or $\mathrm{Na}_{2} \mathrm{CO}_{3}$ on the silica surface alters the work function of the surface significantly, modifying the metalsupport charge transfer and, thus, changing the electronic structure of the deposited clusters. In addition, modification of the morphology by $\mathrm{OH}$ groups can also come into play. The origin of the alteration of the chemical properties of $\mathrm{Au}$ by $\mathrm{NaOH}$ is a subject of future studies.

\section{Conclusion}

We demonstrate that the chemical properties of individual tiny clusters consisting of 5-8 Au atoms are preserved upon exposing to ambient conditions and immersing into distilled water. In addition, properties of these clusters can be modified more easily by additional treatment, as compared to those of larger particles. The $\mathrm{Au}$ clusters deposited on silica surfaces are immersed into water and aqueous $\mathrm{NaOH}$ solutions and, after these treatments under realistic conditions, the chemical properties of the clusters remain unique, non-scalable and size-selective. The control of the cluster size on 
an atom-by-atom basis can be important for obtaining high activity in heterogeneous catalysis, not only in UHV, but also under realistic conditions. Tuning the catalytic properties of metal clusters by adding or abstracting a single atom from a cluster in various reactions will be studied in the future.

\section{Acknowledgements}

Deutsche Forschungsgemeinschaft (DFG) is acknowledged for its financial support through the Sonderforschungsbereich (SFB 513 program (A15)). This work was supported by a Korea Research Foundation Grant funded by the Korean Government (KRF-2006000-C00003)

\section{References}

[1] M. Haruta, S. Tsubota, H. Kobayashi, M. Kageyama, ]. Genet, B. Delmon, J. Catal. 144 (1993) 175

2] M. Valden, X. Lai, D.W. Goodman, Science 281 (1998) 1647.

3] R.E. Palmer. S. Pratontep, H.G. Boyen, Nature Mater. 2 (2003) 443.

[4] U. Landman, B. Yoon, C. Zhang, U. Heiz, M. Arenz, Top. Catal. 44 (2007) 145.
[5] B. Yoon, et al., Science 307 (2005) 403

[6] A. Sanchez, S. Abbet, U. Heiz, W.D. Schneider, H. Hakkinen, R.N. Barnett, U. Landman. J. Phys. Chem. A. 103 (1999) 9573.

[7] KJ. Taylor, C.L. Pettiettehall, O. Cheshnovsky, R.E. Smalley, J. Chem. Phys. 96 (1992) 3319.

[8] T.H. Lee, K.M. Ervin, J. Phys. Chem. 98 (1994) 10023.

[9] D. Stolcic, M. Fischer, G. Ganteför, Y.D. Kim, P. Jena, J. Am. Chem. Soc, 125 (2003) 2848 .

[10] Y.D. Kim, M. Fischer, G. Ganteför, Chem. Phys. Lett. 377 (2003) 170

[1] Y.D. Kim, G. Ganteför, Chem. Phys, Lett. 383 (2004) 80.

[12] S. Lee, C. Fan, T. Wu. S.L. Anderson, J. Am. Chem. Soc. 126 (2004) 5682.

[13] J.M. Antonietti, et al., Phys. Rev. Lett. 94 (2005) 213402.

[14] D.C. Lim, R. Dietsche, M. Bubek, T. Ketterer, G. Gantefoer, Y.D. Kim, Chem. Phys, Lett. 439 (2007) 364

[15] D.C. Lim, R. Dietsche, M. Bubek, G. Ganteför, Y.D. Kim, ChemPhysChem 7 (2006) 1909.

[16] N.D.S. Canning, D. Outka, R.J. Madix, Surf. Sci. 141 (1984) 240.

[17] H. Haberland, M. Mall, M. Moseler, Y. Quiang, T. Reiners, Y. Thurner, J. Vac. Sci. Tecinnol. A, 12 (1994) 2925

[18] H.G. Boyen, et al., Science 297 (2002) 1533

[19] P. Liu, J.A. Rodriguez, J. Chem. Phys. 126 (2007) 164705

[20] D.C. Lim, I. Lopez-Salido, R. Dietsche, M. Bubek, Y.D. Kim, Angew, Chem, Int. Ed. 45 (2006) 2413

[21] W.T. Wallace, R.B. Wyrwas, R.L. Whetten, R. Mitric, V. Bonacic-Koutecky, J. Am. Chem. Soc. 125 (2003) 8408 
